\title{
EFFICIENT TRANSFER OF AgING PROVISIONS IN PRIVATE HEALTH INSURANCE
}

\author{
VOLKER MEIER
}

CESIFO WORKING PAPER NO. 862

CATEGORY 9: INDUSTRIAL ORGANISATION

FEBRUARY 2003

\footnotetext{
An electronic version of the paper may be downloaded

- from the SSRN website: www.SSRN.com

- from the CESifo website: www.CESifo.de
} 


\title{
EFFICIENT TRANSFER OF AGING PROVISIONS IN PRIVATE HEALTH INSURANCE
}

\begin{abstract}
In long-term private health insurance contracts, aging provisions are used to flatten premium profiles. An individual would like to change insurers if she perceives a low service quality. The first-best optimum is characterized by provision transfers which are higher for high risks and may be negative for low risks. Should the actual risk status not be verifiable, provision transfers have to be uniform. Efficient transfers will equalize consumption across periods and states if high risks are deterred from switching. Otherwise, the optimum transfer balances the distortions of incentives for high-risk and low-risk individuals.
\end{abstract}

Keywords: health insurance, multi-period contracts, competition, aging provisions.

JEL Code: D91, G22, I18, K12.

\author{
Volker Meier \\ Ifo Institute \\ Poschingerstr. 5 \\ 81679 Munich \\ Germany \\ meier@ifo.de
}




\section{Introduction}

Competition in the private health insurance sector is frequently accused to be distorted in countries in which the relationship between insurer and insured is governed by a long-term contract. In Germany, Austria and Switzerland, health insurance contracts are generally on a lifetime basis. Parts of the premiums paid to insurers by the young insured are used to flatten the premium profile. A capital stock is accumulated by these contributions which is depleted when the cohort grows old. The surviving insured in a cohort inherit the capital stock of those members in the same age cohort who die early. Interestingly, the individuals who want to change the insurer are treated as if they are dying. They are not entitled to take any provisions accumulated by their premiums to the new insurer. Obviously, this treatment harms competition. People who have paid contributions for a sufficiently long period are effectively deterred from changing the insurer.

This paper addresses the problem how the transfer of aging provisions upon a change of insurers is to be organized as to maximize expected utility of an insured in an ex ante perspective. Gains from insurer changes arise from the existence of idiosyncratic psychic cost shocks in a relation between insurer and insured. If somebody is dissatisfied with her insurer due to a perceived low quality of the service, she would like to terminate the relationship. In fact, Dowd and Feldman (1992), and Hendel and Lizzeri (2000) consider the fear of being locked into a multi-period contract with an insurer providing an unpleasent service as a major obstacle against establishing long-term health insurance contracts in the US.

A first-best solution to the optimization problem can be derived by transposing the concept of a time-consistent health insurance proposed by Cochrane (1995) to long-term health insurance contracts. Cochrane analyzes a framework of short-term contracts with severance payments. Individuals turning into bad risks during the period receive a severance payment reflecting the increase in the present value of future expected health care costs. Conversely, the severance payment for those who remain good risks are negative because their position concerning future expected health care costs has improved. In this fashion, a premium insurance is provided. The negative severance payment can be charged in advance as a premium to finance the positive severance payments, such that negative payments ex post do not occur. Similarly, van de Veen et al. (2000) propose to establish a solidarity fund paying subsidies to high-risk individuals which is financed by manda- 
tory contributions of low-risk individuals. The application to the problem of transferring aging provisions is straightforward. The accumulated aging provision will be reduced for good risks who want to change the insurer while the opposite happens for bad risks. Noting that good risks in old age may exhibit less than per capita lifetime health care cost, it is unsurprising that optimal provision transfer schemes often entail negative provision transfers, or exit premiums, for good risks.

Another concept to avoid unpooling of risks, the guaranteed renewability scheme of Pauly et al. (1995), does not solve the problem to give correct switching incentives for everybody. The idea behind guaranteed renewability is that premiums are the sum of the period premium for the initial low risk status plus the present value of expected cost increases due to becoming a high risk during the period. The scheme translates into a premium profile declining in age. Without provision transfers, it gives correct incentives to switch insurers for low risks. However, those having turned into high risks usually cannot change insurers. A similar scheme is used in the life insurance market where insurers often use long-term front loading contracts, that is, they set relatively high premiums for young insured, in order to avoid risk segmentation among older customers (Hendel and Lizzeri, 2000).

The starting point of the current paper is to translate Cochrane's argument into the framework of provision transfers and psychic costs. For the basic case with risks being verifiable at court, the first-best allocation can be implemented. Provision transfers can be designed as to eliminate any consumption risk while the expected psychic cost is minimized. If a transaction cost is introduced into the basic model, the results are slightly modified. Aging provision transfers only partially cover the transaction cost such that those switching to another insurer experience a consumption loss. Having a transaction cost implies that the first-best allocation can no longer be decentralized. The main contribution of the paper is the derivation of the optimum provision transfer if it has to be uniform. Such a scenario will be relevant if risks are not verifiable. Several types of optima can occur. If high risks are deterred from changing insurers, provision transfers are set as to eliminate consumption risks where the expected psychic cost of low risks is minimized. Should high risks be among both switchers and stayers, the optimum scheme distorts decisions such that too many low-risk individuals are driven out of the original contract. At the same time, some high risks are deterred from leaving their insurer although this amounts to increasing: the expected psychic cost. 
The remainder of the paper is organized as follows. Section 2 introduces the model. The implementation of the first-best allocation in the basic case of verifiable risks is discussed in section 3 . The following section 4 deals with the consequences of integrating a transaction cost into the model. Section 5 focuses on the optimum provision transfer scheme if it has to be uniform since risks cannot be verified at court. Last, section 6 concludes and indicates directions for future research.

\section{The model}

Individuals live for two periods, describing youth and old age. An individual has an income $y_{t}$ in period $t=1,2$. For simplicity, let $y_{1}=y_{2}=y$. Individuals may either be of the low-risk type $l$ or of the high-risk type $h$, where the type may change over time. Initially, all individuals under consideration are of the low-risk type. An individual faces a probability of illness amounting to $p_{1}$ during the first period, associated with a cost $K$. Otherwise, she will stay healthy during period 1 with probability $\left(1-p_{1}\right)$ where $1>p_{1}>0$.

A young low-risk individual will not change her type when becoming old with conditional probability $\lambda$ where $\lambda \in(0,1)$. A fraction $(1-\lambda)$ of the population experiences a deterioration of the state of health and represents a high risk in period 2. We ignore the possibility of an improving physical condition.

In period 2, an individual of type $z \in\{h, l\}$ becomes ill with probability $p_{2}^{z}$ where $p_{2}^{l} \geq p_{1}$ and $1>p_{2}^{h}>p_{2}^{l}>0$. The former assumption captures the stylized fact that the risk of turning ill usually increases in age. An illness will again be associated with cost $K$. Lifetime consumption utility of an individual is given by $U=u\left(c_{1}\right)+u\left(c_{2}\right)$ with $c_{t}$ denoting consumption in period $t$. As individuals display risk aversion, we have $u^{\prime}>0$ and $u^{\prime \prime}<0$. There is no discounting, and the interest rate is set to zero.

Insurers are risk neutral and act in a competitive market. Thus, it is not possible to earn a positive expected profit on any insurance contract. We focus on full insurance contracts with actuarially fair premiums.

Any insurer can observe the state of health of the insured at the beginning of period 1. Contracts stretching over two periods are fixed where only the insured is allowed to terminate the contract after the first period. Consumption in the first period is $c_{1}=y-\pi_{1}$ with $\pi_{1}$ denoting the premium to be paid by a young individual. The premium may include an aging provision 
$r_{1}$ which is charged in order to flatten the premium profile. During young age an idiosyncratic shock occurs, which yields a psychic cost described by the random variable $X$. The realized psychic cost is to be borne by the insured in period 1 and, should the insurance contract continue, also in period 2. $X$ is distributed according to a density function $f(x)$ with mean $E(X)$ being normalized to zero where cumulated density is denoted by $F(x)$. The cost reflects the subjective perceived service quality. It arises from encounters with employees of the insurer, which may be agreeable (negative cost), normal (approximately zero cost) or uncomfortable (positive cost). The psychic cost does not affect marginal utility of consumption. If an individual observes a cost $x$ in period 1 , the same realization occurs in period 2 unless the contract is terminated. Dissatisfying contacts with representatives of the insurer certainly constitute an important reason why individuals change insurers. After period 1, an individual may change her insurer. All insurers are able to observe the modified state of health of the insured.

Let $c_{s}$ be the level of consumption after switching while $c_{\tau}$ is consumption when the individual remains with the old insurer. If $x$ denotes the realized psychic cost if the relationship with the old insurer is continued, the insured chooses to change the insurer if, and only if,

$$
u\left(c_{s}\right)-E(X)>u\left(c_{\tau}\right)-x .
$$

Recalling that $E(X)=0$, it follows that all individuals of the risk group $z$ will change insurers if the psychic cost exceeds the threshold

$$
x^{z}=u\left(c_{\tau}^{z}\right)-u\left(c_{s}^{z}\right)
$$

A share $F\left(x^{z}\right)$ of the original insured of type $z$ stay with the old insurer, while the fraction $\left(1-F\left(x^{z}\right)\right)$ terminates the contract. The premium $\pi_{2}$ is paid by an insured in period 2 who does not change her insurer. It depends exclusively on the state of health at the beginning of the contract. In this event, secondperiod consumption equals $c_{2}=y-\pi_{2}$. In contrast, $\pi^{z}\left(r^{z}\right)=p_{2}^{z} K-r^{z}$, the premium to be paid by an old individual who has switched to another insurer, depends on $z$, the current state of health, and $r^{z}$, the provision transferred from the previous insurer. The latter may vary according to the current state of health. Hence, for switchers of type $z$ second-period consumption is given by $c_{2}=y-\pi^{z}$. The provision transfer is either specified in the contract with the old insurer or set by public regulation. While both cases lead to the same results in the current model, the latter scenario would clearly be more 
realistic. Adhering to a legal standard is much easier than deviating from this standard in insurance contracts.

\section{Optimum insurance with verifiable risks}

In order to attract clients, any insurer designs contracts as to maximize expected utility of an individual, taking into account possible switches to another insurer. Each insurer contracting with a young individual will choose premiums and provision transfers subject to its budget constraint. We arrive at the Lagrangian

$$
\begin{aligned}
L\left(\pi_{1}, \pi_{2}, r^{l}, r^{h}, \kappa\right)= & u\left(y-\pi_{1}\right) \\
& +\lambda F\left(x^{l}\right)\left[u\left(y-\pi_{2}\right)-E\left(X \mid x<x^{l}\right)\right] \\
& +(1-\lambda) F\left(x^{h}\right)\left[u\left(y-\pi_{2}\right)-E\left(X \mid x<x^{h}\right)\right] \\
& +\lambda\left(1-F\left(x^{l}\right)\right) u\left(y-p_{2}^{l} K+r^{l}\right) \\
& +(1-\lambda)\left(1-F\left(x^{h}\right)\right) u\left(y-p_{2}^{h} K+r^{h}\right) \\
& +\kappa\left[\pi_{1}+\pi_{2}\left[\lambda F\left(x^{l}\right)+(1-\lambda) F\left(x^{h}\right)\right]\right. \\
& -\left[p_{1}+\lambda F\left(x^{l}\right) p_{2}^{l}+(1-\lambda) F\left(x^{h}\right) p_{2}^{h}\right] K \\
& \left.-\left[r^{l} \lambda\left(1-F\left(x^{l}\right)\right)+r^{h}(1-\lambda)\left(1-F\left(x^{h}\right)\right)\right]\right],
\end{aligned}
$$

where $\kappa$ denotes the Lagrange multiplier associated with the budget constraint

$$
\begin{aligned}
& \pi_{1}+\pi_{2}\left[\lambda F\left(x^{l}\right)+(1-\lambda) F\left(x^{h}\right)\right] \\
& -\left[p_{1}+\lambda F\left(x^{l}\right) p_{2}^{l}+(1-\lambda) F\left(x^{h}\right) p_{2}^{h}\right] K \\
& -\left[r^{l} \lambda\left(1-F\left(x^{l}\right)\right)+r^{h}(1-\lambda)\left(1-F\left(x^{h}\right)\right)\right] \\
\geq & 0 .
\end{aligned}
$$

Notice that individuals of type $z$ who stay with the original insurer face a mean psychic cost of $E\left(X \mid x<x^{z}\right)$. Only a share $\lambda F\left(x^{l}\right)+(1-\lambda) F\left(x^{h}\right)$ of the initially insured remain with the old insurer and pay premiums in the second period. The collected premiums have to cover the expected health care cost of the insured, $\left[p_{1}+\lambda_{1} F\left(x^{l}\right) p_{2}^{l}+(1-\lambda) F\left(x^{h}\right) p_{2}^{h}\right] K$, and the provision transfers, $r^{l} \lambda\left(1-F\left(x^{l}\right)\right)+r^{h}(1-\lambda)\left(1-F\left(x^{h}\right)\right)$. The necessary first-order conditions, being derived in detail in the appendix, are 


$$
\begin{gathered}
\frac{\partial L}{\partial \pi_{1}}=-u^{\prime}\left(y-\pi_{1}\right)+\kappa=0 \\
\frac{\partial L}{\partial \pi_{2}}=-\left[\lambda F\left(x^{l}\right)+(1-\lambda) F\left(x^{h}\right)\right]\left[u^{\prime}\left(y-\pi_{2}\right)-\kappa\right] \\
+\lambda f\left(x^{l}\right) \frac{\partial x^{l}}{\partial \pi_{2}} \kappa\left[\pi_{2}-p_{2}^{l} K+r^{l}\right] \\
+(1-\lambda) f\left(x^{h}\right) \frac{\partial x^{h}}{\partial \pi_{2}} \kappa\left[\pi_{2}-p_{2}^{h} K+r^{h}\right] \\
=0, \quad \lambda\left(1-F\left(x^{l}\right)\right)\left[u^{\prime}\left(y-\pi^{l}\right)-\kappa\right] \\
\frac{\partial L}{\partial r^{l}}=\quad+\lambda \frac{\partial F\left(x^{l}\right)}{\partial r^{l}} \kappa\left[\pi_{2}-p_{2}^{l} K+r^{l}\right] \\
=0,
\end{gathered}
$$

The first-order conditions can be interpreted as follows. Increasing the premium in period 1 depresses utility by decreasing first-period consumption according to $-u^{\prime}\left(y-\pi_{1}\right)<0$. At the same time, it raises utility by enhancing the budget of the insurer, which is captured by $\kappa>0$. Raising $\pi_{2}$, the premium in the second period, also has a negative impact on utility, described by $-\left[\lambda F\left(x^{l}\right)+(1-\lambda) F\left(x^{h}\right)\right] u^{\prime}\left(y-\pi_{2}\right)<0$, and a benefit through a higher insurer budget, given by $\kappa\left[\lambda F\left(x^{l}\right)+(1-\lambda) F\left(x^{h}\right)\right]>0$. Further, it increases the number of low risks and high risks who would like to change the insurer because staying with the old insurer is no longer attractive. This reduces both premiums and liabilities of the insurer and raises the amount of provisions to be transferred. These impacts are captured by the terms $\lambda \frac{\partial F\left(x^{l}\right)}{\partial \pi_{2}} \kappa\left[\pi_{2}-\right.$ $\left.p_{2}^{l} K+r^{l}\right]$ for low risks and $(1-\lambda) \frac{\partial F\left(x^{h}\right)}{\partial \pi_{2}} \kappa\left[\pi_{2}-p_{2}^{h} K+r^{h}\right]$ for high risks. 
Increasing the provision transfer for low risks raises utility of those low risks who change the insurer by driving down their premium. At the same time, utility is reduced due to the additional expenditures of the old insurer. These two effects are described by $\lambda\left(1-F\left(x^{l}\right)\right)\left[u^{\prime}\left(y-\pi^{l}\right)-\kappa\right]$. Again, the measure increases the number of low risks who would like to change the insurer because staying is no longer attractive. This reduces both premiums and liabilities of the insurer and raises the amount of provisions to be transferred. These impacts are captured in the term $\lambda \frac{\partial F\left(x^{l}\right)}{\partial r^{l}} \kappa\left[\pi_{2}-p_{2}^{l} K+r^{l}\right]$. The corresponding condition for the optimal transfer of old age provisions of high risks can be interpreted accordingly.

Proposition 1 If risks are verifiable, the first-best solution is achieved by setting provision transfers as to equalize both consumption and premiums across all periods and states.

Proof: If $\pi_{1}=\pi_{2}=\pi^{l}=\pi^{h}$, implying that $r^{l}=p_{2}^{l} K-\pi_{2}$ and $r^{h}=$ $p_{2}^{h} K-\pi_{2}$, all first-order conditions are satisfied. Since the expected health care cost cannot be influenced, and individuals are risk averse, an allocation with the same level of consumption irrespective of period and state must maximize expected utility from consumption. Moreover, insurer changes occur if $x>0$ while individuals stay with the original insurer if $x<0$.

As the individual is risk averse, she clearly likes best a situation in which all risks are covered by the insurers. This solution implies that insurer changes occur if and only if the expected psychic cost is reduced by switching. Therefore, the expected psychic cost is minimized in such an allocation.

It can easily be demonstrated that the optimum can involve a negative provision transfer for low risks. Let $K=10, p_{1}=p_{2}^{l}=0.1, p_{2}^{h}=0.9$, and $\lambda=0.9$. In this case, the total expected health care cost per individual is $E K=10[0.1+0.9 \cdot 0.1+0.1 \cdot 0.9]=2.8$. A flat rate premium for the group as a whole would be $\pi_{1}=\pi_{2}=1.4$. Hence, the provision accumulated would be $r_{1}=0.4$ per individual. A low-risk individual would have to pay $p_{2}^{l} K=1$ as a net premium if she changes her insurer. Thus, if the provision transfer is set as to keep the premium flat, it would amount to $r^{l}=-0.4$. The corresponding provision transfer for high risks is $r^{h}=7.6$.

It should be noted that such a scenario is associated with serious problems in practice. For the majority of the insured the provision transfer is negative to a substantial extent. Although the premium in the first period 
was higher than necessary to cover expected costs, the insured is asked to pay an additional exit premium.

A second problem lies in the fact that the insurer has an incentive to overestimate the risks in the remaining population. Should the incentive to quit arise from an unfort unate realization of the risk structure, the insurer has a strong argument to reduce the transfer of aging provisions. Third, it can become attractive to choose a short-term contract or even stay uninsured in the first period if the individual has superior information on his good health status. If the threat of a negative provision transfer exists, the incentive to remain uninsured during youth becomes stronger for individuals being certain to represent good risks later on.

\section{Transaction costs}

Transaction costs are in many cases not negligible if there is a change of insurers. Usually a new medical investigation is necessary to assess the risk the individual represents. Further, it is not unusual in practice that the underwriter receives a bonus for any new contract. How does this aspect of existing transaction costs affect the conclusions with respect to the transfer of old age provisions? Denoting the transaction cost per individual changing her insurer by $T$, the Lagrangian of the optimization problem now reads

$$
\begin{aligned}
L\left(\pi_{1}, \pi_{2}, r^{l}, r^{h}, \kappa\right)= & u\left(y-\pi_{1}\right) \\
& +\lambda F\left(x^{l}\right)\left[u\left(y-\pi_{2}\right)-E\left(X \mid x<x^{l}\right)\right] \\
& +(1-\lambda) F\left(x^{h}\right)\left[u\left(y-\pi_{2}\right)-E\left(X \mid x<x^{h}\right)\right] \\
& +\lambda\left(1-F\left(x^{l}\right)\right) u\left(y-\pi^{l}\right) \\
& +(1-\lambda)\left(1-F\left(x^{h}\right)\right) u\left(y-\pi^{h}\right) \\
& +\kappa\left[\pi_{1}+\pi_{2}\left[\lambda F\left(x^{l}\right)+(1-\lambda) F\left(x^{h}\right)\right]\right. \\
& -\left[p_{1}+\lambda F\left(x^{l}\right) p_{2}^{l}+(1-\lambda) F\left(x^{h}\right) p_{2}^{h}\right] K \\
& \left.-\left[r^{l} \lambda\left(1-F\left(x^{l}\right)\right)+r^{h}(1-\lambda)\left(1-F\left(x^{h}\right)\right)\right]\right]
\end{aligned}
$$

with $\pi^{l}=p_{2}^{l} K+T-r^{l}$ and $\pi^{h}=p_{2}^{h} K+T-r^{h}$. It should be noted that none of the first-order conditions of the basic model is affected. Yet, the conclusions to be drawn from these conditions change due to the transaction cost. 
Proposition 2 The optimum with transaction costs consists of a premium structure in which $\pi_{2}<\pi_{1}, \pi_{1}<\pi^{l}$, and $\pi_{1}<\pi^{h}$. Moreover, $r^{h}>p_{2}^{l} K-\pi_{2}$ and $r^{l}>p_{2}^{h} K-\pi_{2}$ hold.

Proof: See appendix.

The main message of the proposition is that premiums will be higher for switchers than for those who continue the contract. This implies that some of those who would save in expected psychic cost by changing the insurer are deterred from switching. The reason for this outcome lies in the fact that the gain in expected psychic cost may be small compared to the transaction cost associated with underwriting a new contract. Hence, the existence of transaction costs prevents that the first-best allocation, which would still require a flat consumption profile, can be achieved by decentralized decisionmaking. On the other hand, the optimum aging provision transfer partially covers the transaction cost. Since there is a positive probability of having to change the insurer due to a high psychic cost, the loss through the transaction cost is shared with those who stay with the original insurer. Noting that there is still a tendency to equalize consumption across periods, consumption of young individuals falls short of consumption of old stayers while it exceeds consumption of old switchers.

\section{$5 \quad$ Non-verifiable risks}

The first-best allocation derived in the section 3 implies that the provision transfer to a new insurer will be higher for a high risk than for a low risk. Hence, it lies in the interest of a new insurer to declare that the applicant is a high risk. Conversely, an insurer being certain that a customer will leave the community may try to save provision transfers by declaring that the individual represents a low risk. If the true risk is not verifiable by judges at a low cost, a second-best alternative may lie in a transfer that exclusively depends on age, but cannot be differentiated according to risk. Nevertheless, the new insurer calculates the premium according to the correct risk. The optimization procedure now requires to set the same provision transfer $r$ for 
both risk types. The Lagrangian is

$$
\begin{aligned}
L\left(\pi_{1}, \pi_{2}, r, \kappa\right)= & u\left(y-\pi_{1}\right) \\
& +\lambda F\left(x^{l}\right)\left[u\left(y-\pi_{2}\right)-E\left(X \mid x<x^{l}\right)\right] \\
& +(1-\lambda) F\left(x^{h}\right)\left[u\left(y-\pi_{2}\right)-E\left(X \mid x<x^{h}\right)\right] \\
& +\lambda\left(1-F\left(x^{l}\right)\right) u\left(y-p_{2}^{l} K+r\right) \\
& +(1-\lambda)\left(1-F\left(x^{h}\right)\right) u\left(y-p_{2}^{h} K+r\right) \\
& +\kappa\left[\pi_{1}+\pi_{2}\left[\lambda F\left(x^{l}\right)+(1-\lambda) F\left(x^{l}\right)\right]\right. \\
& -\left[p_{1}+\lambda F\left(x^{l}\right) p_{2}^{l}+(1-\lambda) F\left(x^{h}\right) p_{2}^{h}\right] K \\
& \left.-r\left[\lambda\left(1-F\left(x^{l}\right)\right)+(1-\lambda)\left(1-F\left(x^{h}\right)\right)\right]\right] .
\end{aligned}
$$

The first-order conditions are now given by

$$
\begin{gathered}
\frac{\partial L}{\partial \pi_{1}}=-u^{\prime}\left(y-\pi_{1}\right)+\kappa=0 \\
\frac{\partial L}{\partial \pi_{2}}=\quad-\left[\lambda F\left(x^{l}\right)+(1-\lambda) F\left(x^{h}\right)\right]\left[u^{\prime}\left(y-\pi_{2}\right)-\kappa\right] \\
\quad+\lambda \frac{\partial F\left(x^{l}\right)}{\partial \pi_{2}} \kappa\left[\pi_{2}-p_{2}^{l} K+r\right]+(1-\lambda) \frac{\partial F\left(x^{h}\right)}{\partial \pi_{2}} \kappa\left[\pi_{2}-p_{2}^{h} K+r\right] \\
=\quad 0, \\
\frac{\partial L}{\partial r}=\quad \lambda\left(1-F\left(x^{l}\right)\right)\left[u^{\prime}\left(y-\pi^{l}\right)-\kappa\right]+\lambda \frac{\partial F\left(x^{l}\right)}{\partial r} \kappa\left[\pi_{2}-p_{2}^{l} K+r\right] \\
+(1-\lambda)\left[\left(1-F\left(x^{h}\right)\right)\left[u^{\prime}\left(y-\pi^{h}\right)-\kappa\right]+\frac{\partial F\left(x^{h}\right)}{\partial r} \kappa\left[\pi_{2}-p_{2}^{h} K+r\right]\right] \\
=0 .
\end{gathered}
$$

In principle, several types of optima can occur if there are no restrictions on possible values of parameters and variables. These can be ordered according to the level of the transfer. At a given psychic cost and a fixed provision transfer, the incentive to switch to another insurer is always weakly stronger for the low-risk type. First, a solution in which everybody is tied to the old insurer can be achieved by setting the provision transfer arbitrarily high in the negative range. Second, it may be the case that some low risks change, while all high risks stay with the original insurer. Third, all low risks may 
change while all high risks stay. Fourth, the share of stayers and switchers among both types can be strictly positive. Fifth, all low risks and some high risks may leave the original insurer. Last, everybody may leave the old insurer.

Clearly, if the provision transfer is varied, either the third or the fourth type may occur, but never both types. Recalling that the equation $u\left(y-\pi_{2}\right)-$ $x^{z}=u\left(y-\pi^{z}\right)$ defines the psychic cost at which an individual is indifferent between switching and staying, it turns out that

$$
x^{h}-x^{l}=u\left(y-p_{2}^{l} K+r\right)-u\left(y-p_{2}^{h} K+r\right)
$$

provided that there is a positive share of switchers and stayers of both types. Typically, if the support of the random variable $X$ is on a relatively small interval and the contrast between low risks and high risks is sharp, a situation with positive fractions of switchers and stayers of both types cannot occur. On the other hand, if the support of $X$ is on a sufficiently large interval, lowrisk individuals with a small or negative psychic cost will face an incentive to change insurers only if also high risks with a high psychic cost would like to leave the original insurer. Should the support of $X$ be on the interval $(-\infty,+\infty)$ while the provision transfer is finite, only the fourth switcher profile can arise.

Two candidates for an optimum can be excluded. Obviously, a scheme in which everybody quits the insurer can never constitute an optimum. Compared to a situation in which everybody sticks to the contract, there is no gain in expected psychic cost. At the same time, risk-averse individuals cannot capture the full gains from pooling risks. A similar argument applies if risks are separated where all low risks change the insurer. Trying to construct a scheme being equivalent to the no-switch allocation is not compatible with individual rationality.

Proposition 3 An optimum never consists of a situation in which all low risks change the insurer and all high risks stay with the old insurer.

Proof: Since expected consumption cannot be influenced, a separation of risks yields a strictly lower expected utiliy than the no-switch equlibrium with $r=-\infty$ and $\pi_{1}=\pi_{2}$ unless $\pi_{1}=\pi_{2}=\pi^{l}$. However, when $\pi_{2}=\pi^{l}$ holds, the low risks with a psychic cost $x<0$ are better off when staying with the old insurer. 
A separation of risks can never represent an optimum. First, should premiums not be equal across all states and periods, expected utility is higher if everybody stays with the old insurer. Second, if the condition on premiums is satisfied, the individuals with a low psychic cost would be better off if they did not change the insurer.

The next proposition characterizes the optimum should high risks be kept in the original contract.

Proposition 4 An optimum where only some low risks but no high-risk individual change the insurer is characterized by $\pi_{1}=\pi_{2}=\pi^{l}$. If such a scheme keeps all high risks in the original contract, expected utility is higher than if there are no insurer changes.

Proof: It can easily be checked that setting $\pi_{1}=\pi_{2}=\pi^{l}$ satisfies the first-order conditions provided that no high-risk individual changes. Expected utility then amounts to

$$
E U=2 u\left(y-\frac{p_{1}+\lambda p_{2}^{l}+(1-\lambda) p_{2}^{h}}{2} K\right)-\lambda F(0) E(X \mid x<0),
$$

which exceeds maximum expected utility subject to no switches by $-\lambda F(0) E(X \mid x<0)>0$.

If only low-risk individuals change the insurer, a premium scheme can be implemented which resembles the first-best allocation. While the consumption risk is entirely borne by the insurers, the expected psychic cost of low risks is minimized. All low-risk individuals with $x>0$ will change the insurer while those with $x<0$ will stay. However, the high-risk individuals with $x>0$ will not change the insurer now. The provision transfer for $\pi^{l}=\pi_{1}=\pi_{2}$ can then be derived from the two budget equations

$$
\pi^{l}=p_{2}^{l} K-r
$$

and

$$
\begin{aligned}
\pi^{l}\left[1+\lambda F\left(x^{l}\right)+(1-\lambda)\right]= & {\left[p_{1}+\lambda F\left(x^{l}\right) p_{2}^{l}+(1-\lambda) p_{2}^{h}\right] K } \\
& +r \lambda\left(1-F\left(x^{l}\right)\right)
\end{aligned}
$$


Isolating $\pi^{l}$ and solving for $r$ then yields

$$
\begin{aligned}
r & =\frac{p_{2}^{l}-\frac{p_{1}+\lambda F\left(x^{l}\right) p_{2}^{l}+(1-\lambda) p_{2}^{h}}{1+\lambda F\left(x^{l}\right)+(1-\lambda)}}{1+\frac{\lambda\left(1-F\left(x^{l}\right)\right)}{1+\lambda F\left(x^{l}\right)+(1-\lambda)}} K \\
& =\frac{p_{2}^{l}\left[1+\lambda F\left(x^{l}\right)+(1-\lambda)\right]-\left[p_{1}+\lambda F\left(x^{l}\right) p_{2}^{l}+(1-\lambda) p_{2}^{h}\right]}{1+\lambda F\left(x^{l}\right)+(1-\lambda)+\lambda\left(1-F\left(x^{l}\right)\right)} K \\
& =\frac{1}{2}\left[p_{2}^{l}-p_{1}+(1-\lambda)\left[p_{2}^{l}-p_{2}^{h}\right]\right] K .
\end{aligned}
$$

This term is negative for $p_{1}=p_{2}^{l}$ while it may be positive if $p_{1}<p_{2}^{l}$ holds. The optimum transfer will be negative if aging provisions are relatively small due to little or no age-specific increases in the illness risk. In contrast, if there is a marked increase in the illness probability for those who remain low risks with rising age, the provision transfer can also be positive. However, it will always fall short of the average aging provision

$$
\begin{aligned}
r_{1} & =\pi^{l}-p_{1} K \\
& =p_{2}^{l} K-\frac{1}{2}\left[p_{2}^{l}-p_{1}+(1-\lambda)\left[p_{2}^{l}-p_{2}^{h}\right]\right] K-p_{1} K \\
& =\frac{1}{2}\left[p_{2}^{l}-p_{1}-(1-\lambda)\left[p_{2}^{l}-p_{2}^{h}\right]\right] K .
\end{aligned}
$$

If the optimum displays the feature that high risks are among the switchers, it is no longer possible to get rid of the consumption risk. Proposition 5 characterizes the optimum if all low risks terminate the long-term contract.

Proposition 5 In any optimum in which all low risks change the insurer while some high risks change and some high risks stay with the old insurer, the optimum is characterized by $\pi^{l}<\pi_{1}<\pi_{2}<\pi^{h}$.

Proof: See appendix.

All low risks change the insurer if they can save contributions while the loss in psychic cost of those being satisfied with the old insurer may be relatively small. In such an optimum, the premium for those high risks who switch exceeds the premium of stayers. Therefore, some individuals do not change insurers although this would reduce their expected psychic cost. This property of such an optimum arises because raising the provision 
transfer is partly used to increase consumption of the low-risk switchers. For these individuals, marginal utility is already low, implying a reduced marginal benefit of the transfer. Noting that all stayers are high risks, it is unsurprising that the premium they have to pay exceeds the premium in the first period.

A similar premium structure arises if we consider an optimum where some of the low risks remain with the old insurer.

Proposition 6 In any optimum with strictly positive fractions of switchers and stayers of both types, the optimum is characterized by $\pi^{l}<\pi_{2}<\pi^{h}$.

Proof: See appendix.

The proposition can easily be interpreted. With positive fractions of switchers and stayers of both types and a uniform provision transfer, the indifferent low-risk individual exhibits a smaller psychic cost than the indifferent high-risk individual. If the psychic cost of the indifferent low-risk individual does not fall short of the mean psychic cost, too many high-risk individuals stay with the old insurer in terms of the psychic cost. At the same time, nobody is induced to change despite being satisfied with the old insurer. Therefore, an efficiency gain can be achieved by increasing the provision transfer, inducing more individuals to change the insurer. Conversely, if the psychic cost of the indifferent high-risk individual does not exceed the mean psychic cost, too many low-risk individuals change the insurer, while nobody is induced to stay despite being dissatisfied with the old insurer. Therefore, an efficiency gain can be achieved by reducing the provision transfer, lowering the share of switchers. The optimum balances the distortions in such a fashion that too many low-risk individuals are induced to change the insurer while too many high risks stick to the old insurer.

Depending on the parameters of the optimization problem, four solution types may occur. First, it may be the case that provision transfers are set very high in the negative range to deter any insurer change. This is an optimum if the psychic cost does not exist. Nothing can then be gained in terms of expected utility ex ante if people are allowed to terminate the insurance contract. Second, the scheme may equalize premiums for low risks where only some low risks change the insurer while all high risks stick to the old contract. This will certainly constitute the optimum if there is indeed no switching incentive for high risks and the share of high risks is very small. The efficiency losses, which are given by opportunities to reduce the psychic 
cost of high risks, are negligible if the share of high risks goes to zero. Third, if the share of low risks is very small, the optimum will be designed such that switching high risks will lose small amounts in consumption while all low risks will choose a new contract. Fourth, if high risks and low risks are close to each other in terms of illness risk, the transfer will be set such that there is a positive share of stayers and switchers of both types.

\section{Conclusion}

It has been shown that the first-best allocation with equalized consumption levels across all states and periods at a minimum expected psychic cost can be reached if risks are verifiable and no transaction cost exists. The provision transfer scheme upon insurer switches will exhibit type-specific transfers which can well be negative for good risks. This basic message is slightly modified if a transaction cost associated with underwriting a new contract exists. Since only a fraction of the transaction cost is taken into account in the aging provision transfer, switching to another insurer will be accompanied by a loss in consumption.

If risks are not verifiable for judges, only uniform provision transfers can be used. Should individuals representing high risks be deterred from changing their insurers, the optimum achieves a situation in which the consumption risk is fully borne by the insurers. Again, negative provision transfers as a feature of the optimum cannot be excluded. If high risks are among the switchers, the optimum gives a balanced distorted incentive to terminate the initial contract. Given the goal to minimize expected psychic cost, the incentive is too strong for low risks and too weak for high risks.

The main insight of the study for policy-makers is that the optimum transfer scheme may entail negative provision transfers even if uniform transfers have to be applied. Should such exit premiums be not applicable in the legal system, the current practice of a uniform zero transfer does not seem unreasonable.

Several important issues have not been considered in the analysis. First, having an exogenous psychic cost, the insurer's effort to reduce this cost is neglected. Clearly, increasing provision transfers for any group of individuals should raise such efforts. Second, there may be more space for competition. In particular, we may find a differentiation according to service quality and administrative costs due to en hanced competition. Third, an impact on profit 
margins does not occur in the current framework by setting these to zero. Fourth, we may have an asymmetric information problem with respect to health status for older individuals. It is certainly plausible that the insured receives more information on the evolution of his health than his insurer. Should such an adverse selection problem arise, the tendency against positive provision transfers will presumably become stronger.

\section{Appendix}

\section{Derivation of first-order conditions}

Notice that

$$
\begin{aligned}
\frac{\partial F\left(x^{l}\right)}{\partial \pi_{2}}= & \frac{\partial F\left(x^{l}\right)}{\partial x} \frac{\partial x^{l}}{\partial \pi_{2}} \\
= & f\left(x^{l}\right) \frac{\partial x^{l}}{\partial \pi_{2}}=-f\left(x^{l}\right) u^{\prime}\left(y-\pi_{2}\right)<0 \\
& \frac{\partial x^{l}}{\partial r^{l}}=-u^{\prime}\left(y-\pi^{l}\right),
\end{aligned}
$$

and

$$
\begin{aligned}
\frac{\partial E\left(X \mid x<x^{l}\right)}{\partial \pi_{2}} & =\frac{\partial E\left(X \mid x<x^{l}\right)}{\partial x^{l}} \frac{\partial x^{l}}{\partial \pi_{2}} \\
& =\frac{\int_{-\infty}^{x^{l}} f(x) d x x^{l} f\left(x^{l}\right)-\int_{-\infty}^{x^{l}} x f(x) d x f\left(x^{l}\right)}{\left[\int_{-\infty}^{x^{l}} f(x) d x\right]^{2}} \frac{\partial x^{l}}{\partial \pi_{2}} \\
& =\frac{f\left(x^{l}\right)}{F\left(x^{l}\right)}\left[x^{l}-E\left(X \mid x<x^{l}\right)\right] \frac{\partial x^{l}}{\partial \pi_{2}} \\
& =-f\left(x^{l}\right) \frac{x^{l}-E\left(X \mid x<x^{l}\right)}{F\left(x^{l}\right)} u^{\prime}\left(y-\pi_{2}\right) .
\end{aligned}
$$

Recalling the threshold definition (2), this allows us to simplify the first-order conditions as follows: 


$$
\begin{aligned}
\frac{\partial L}{\partial \pi_{2}}= & -\left[\lambda F\left(x^{l}\right)+(1-\lambda) F\left(x^{h}\right)\right]\left[u^{\prime}\left(y-\pi_{2}\right)-\kappa\right] \\
& +\lambda \frac{\partial F\left(x^{l}\right)}{\partial \pi_{2}}\left[\left[u\left(y-\pi_{2}\right)-E\left(X \mid x<x^{l}\right)\right]\right. \\
& \left.-u\left(y-\pi^{l}\right)+\kappa\left[\pi_{2}-p_{2}^{l} K+r^{l}\right]\right] \\
& -\lambda F\left(x^{l}\right) \frac{\partial E\left(X \mid x<x^{l}\right)}{\partial \pi_{2}} \\
& +(1-\lambda) \frac{\partial F\left(x^{l}\right)}{\partial \pi_{2}}\left[\left[u\left(y-\pi_{2}\right)-E\left(X \mid x<x^{h}\right)\right]\right. \\
& \left.-u\left(y-\pi^{h}\right)+\kappa\left[\pi_{2}-p_{2}^{h} K+r^{h}\right]\right] \\
& -(1-\lambda) F\left(x^{h}\right) \frac{\partial E\left(X \mid x<x^{h}\right)}{\partial \pi_{2}} \\
= & -\left[\lambda F\left(x^{l}\right)+(1-\lambda) F\left(x^{h}\right)\right]\left[u^{\prime}\left(y-\pi_{2}\right)-\kappa\right] \\
& +\lambda f\left(x^{l}\right) \frac{\partial x^{l}}{\partial \pi_{2}}\left[\left[u\left(y-\pi_{2}\right)-x^{l}\right]\right. \\
& \left.-u\left(y-\pi^{l}\right)+\kappa\left[\pi_{2}-p_{2}^{l} K+r^{l}\right]\right] \\
& +(1-\lambda) f\left(x^{h}\right) \frac{\partial x^{h}}{\partial \pi_{2}}\left[\left[u\left(y-\pi_{2}\right)-x^{h}\right]\right. \\
& \left.-\left[u\left(y-\pi^{h}\right)-E(X)\right]+\kappa\left[\pi_{2}-p_{2}^{h} K+r^{h}\right]\right] \\
= & -\left[\lambda F\left(x^{l}\right)+(1-\lambda) F\left(x^{h}\right)\right]\left[u^{\prime}\left(y-\pi_{2}\right)-\kappa\right] \\
& \left.+\lambda f\left(x^{l}\right) \frac{\partial x^{l}}{\partial \pi_{2}} \kappa\left[\pi_{2}-p_{2}^{l} K+r^{l}\right]\right] \\
& \left.+(1-\lambda) f\left(x^{h}\right) \frac{\partial x^{h}}{\partial \pi_{2}} \kappa\left[\pi_{2}-p_{2}^{h} K+r^{h}\right]\right] \\
= & 0,
\end{aligned}
$$




$$
\begin{aligned}
& \frac{\partial L}{\partial r^{l}}=\lambda\left(1-F\left(x^{l}\right)\right)\left[u^{\prime}\left(y-\pi^{l}\right)-\kappa\right] \\
& +\lambda \frac{\partial F\left(x^{l}\right)}{\partial r^{l}}\left[\left[u\left(y-\pi_{2}\right)-E\left(X \mid x<x^{l}\right)\right]\right. \\
& \left.-u\left(y-\pi^{l}\right)+\kappa\left[\pi_{2}-p_{2}^{l} K+r^{l}\right]\right] \\
& -\lambda F\left(x^{l}\right) \frac{\partial E\left(X \mid x<x^{l}\right)}{\partial r^{l}} \\
& =\lambda\left(1-F\left(x^{l}\right)\right)\left[u^{\prime}\left(y-\pi^{l}\right)-\kappa\right] \\
& +\lambda \frac{\partial F\left(x^{l}\right)}{\partial r^{l}}\left[\left[u\left(y-\pi_{2}\right)-x^{l}\right]\right. \\
& \left.-u\left(y-\pi^{l}\right)+\kappa\left[\pi_{2}-p_{2}^{l} K+r^{l}\right]\right] \\
& =\lambda\left(1-F\left(x^{l}\right)\right)\left[u^{\prime}\left(y-\pi^{l}\right)-\kappa\right] \\
& +\lambda \frac{\partial F\left(x^{l}\right)}{\partial r^{l}} \kappa\left[\pi_{2}-p_{2}^{l} K+r^{l}\right] \\
& =0 \text {, } \\
& \begin{aligned}
\frac{\partial L}{\partial r^{h}}= & (1-\lambda)\left(1-F\left(x^{h}\right)\right)\left[u^{\prime}\left(y-\pi_{x}^{h}\right)-\kappa\right] \\
& +(1-\lambda) \frac{\partial F\left(x^{h}\right)}{\partial r^{h}}\left[\left[u\left(y-\pi_{2}\right)-E\left(X \mid x<x^{h}\right)\right]\right. \\
& \left.-u\left(y-\pi^{h}\right)+\kappa\left[\pi_{2}-p_{2}^{h} K+r^{h}\right]\right] \\
& -(1-\lambda) F\left(x^{h}\right) \frac{\partial E\left(X \mid x<x^{h}\right)}{\partial r^{h}} \\
= & (1-\lambda)\left(1-F\left(x^{h}\right)\right)\left[u^{\prime}\left(y-\pi^{h}\right)-\kappa\right] \\
& +(1-\lambda) \frac{\partial F\left(x^{h}\right)}{\partial r^{h}}\left[\left[u\left(y-\pi_{2}\right)-x^{h}\right]\right. \\
& \left.-u\left(y-\pi^{h}\right)+\kappa\left[\pi_{2}-p_{2}^{h} K+r^{h}\right]\right] \\
= & (1-\lambda)\left(1-F\left(x^{h}\right)\right)\left[u^{\prime}\left(y-\pi^{h}\right)-\kappa\right] \\
& +(1-\lambda) \frac{\partial F\left(x^{h}\right)}{\partial r^{h}} \kappa\left[\pi_{2}-p_{2}^{h} K+r^{h}\right] \\
= & 0 .
\end{aligned}
\end{aligned}
$$

\section{Proof of Proposition 2}

Notice that $\pi_{2}-p_{2}^{z} K+r^{z}=\pi_{2}-\left[\pi^{z}-T\right]$ for $z \epsilon\{h, l\}$. Suppose first that $\pi^{z} \leq \pi_{2}$ for $z=h, l$. The optimality conditions (7) and (8) will then be 
satisfied only if $u^{\prime}\left(y-\pi^{z}\right)>\kappa$. Since the utility function is strictly concave, $u^{\prime}\left(y-\pi_{2}\right)>\kappa$ would hold then. Consequently, the first-order condition (6) will be violated.

Next, consider the case $\pi^{z} \leq \pi_{2}<\pi^{w}$ where $w \neq z$. Let $z=l$. The first-order condition (7) then requires $u^{\prime}\left(y-\pi^{l}\right)>\kappa$. This in turn implies $u^{\prime}\left(y-\pi_{2}\right)>\kappa$ and $u^{\prime}\left(y-\pi^{h}\right)>\kappa$ due to the strict concavity of $u$. Noticing (8), $u^{\prime}\left(y-\pi^{h}\right)>\kappa$ is associated with $\pi_{2}>\pi^{h}-T$. As a consequence, the first-order condition (6) cannot be fulfilled. An analogous argument applies for $z=h$. Thus, $\pi^{l}>\pi_{2}$ and $\pi^{h}>\pi_{2}$ have to hold in any optimum.

Now suppose that $\min \left\{\pi^{h}, \pi^{l}\right\} \geq \pi_{2}+T$ is a property of the optimum. The optimality conditions $(7)$ and (8) then require $u^{\prime}\left(y-\pi^{z}\right) \leq \kappa$ with $z=h, l$. Due to the strict concavity of $u$, this implies $u^{\prime}\left(y-\pi_{2}\right)<\kappa$. The optimality condition (6) would be violated in this case.

Last, consider the case $\pi_{2}<\pi^{z}<\pi_{2}+T \leq \pi^{w}$ where $w \neq z$. Let $w=l$. The first-order condition (7) then requires $u^{\prime}\left(y-\pi^{l}\right) \leq \kappa$. This in turn implies $u^{\prime}\left(y-\pi^{h}\right)<\kappa$ due to the strict concavity of $u$. This situation contradicts the optimality condition (8). An analogous argument applies for $w=h$.

Hence, $\pi^{l}<\pi_{2}+T$ and $\pi^{h}<\pi_{2}+T$ have to hold in any optimum, being equivalent to $r^{h}>p_{2}^{l} K-\pi_{2}$ and $r^{l}>p_{2}^{h} K-\pi_{2}$. According to (7), (8), and (6), this requires $u^{\prime}\left(y-\pi^{l}\right)>\kappa, u^{\prime}\left(y-\pi^{h}\right)>\kappa$, and $u^{\prime}\left(y-\pi_{2}\right)<\kappa$. Recalling that $u^{\prime}\left(y-\pi_{1}\right)=\kappa$ has to hold due to $(5)$, this implies $\pi_{2}<\pi_{1}$.

\section{Proof of Proposition 5}

Notice that $\pi^{l}<\pi^{h}$ must necessarily hold. Suppose first that $\pi^{h} \leq \pi_{2}$. The first-order condition (12) would then imply $u^{\prime}\left(y-\pi_{2}\right)-\kappa \leq 0$ for the situation in which all low risks and some high risks change the insurer. This in turn yields $u^{\prime}\left(y-\pi^{h}\right)-\kappa \leq 0$ and $u^{\prime}\left(y-\pi^{l}\right)-\kappa<0$. However, in this situation we would have $\frac{\partial L}{\partial r}<0$, which contradicts the optimality condition (13). Hence, $\pi^{h}>\pi_{2}$ must be valid in any optimum of this type. Since $\frac{\partial F\left(x^{h}\right)}{\partial \pi_{2}}<0$, we must have $u^{\prime}\left(y-\pi_{2}\right)-\kappa>0$ according to (12). Noting that $u^{\prime}\left(y-\pi_{1}\right)-\kappa=0$ and $u$ is strictly concave, it follows that $\pi_{2}>\pi_{1}$. Recalling $\frac{\partial F\left(x^{h}\right)}{\partial r}<0$, the first-order condition (13) can be satisfied only if $u^{\prime}\left(y-\pi^{l}\right)-\kappa<0$ holds, implying $\pi_{1}>\pi^{l}$. 


\section{Proof of Proposition 6}

Notice that $\pi^{l}<\pi^{h}$ must necessarily hold. Suppose first that $\pi^{l}<\pi^{h} \leq \pi_{2}$. The first-order condition (12) would then imply $u^{\prime}\left(y-\pi_{2}\right)-\kappa<0$. This in turn yields $u^{\prime}\left(y-\pi^{h}\right)-\kappa<0$ and $u^{\prime}\left(y-\pi^{l}\right)-\kappa<0$. However, in this situation we would have $\frac{\partial L}{\partial r}<0$, which contradicts the optimality condition (13). Hence, $\pi^{h}>\pi_{2}$ must be valid in any optimum of this type. Should now $\pi_{2} \leq \pi^{l}<\pi^{h}$ hold, the optimality condition (12) would yield $u^{\prime}(y-$ $\left.\pi_{2}\right)-\kappa>0$. In this event, we would arrive at $u^{\prime}\left(y-\pi^{l}\right)-\kappa>0$ and $u^{\prime}(y-$ $\left.\pi^{h}\right)-\kappa>0$. Recalling $\frac{\partial F\left(x^{h}\right)}{\partial r}<0$, the first-order condition (13) would be violated. Therefore, $\pi_{2}>\pi^{l}$ must necessarily hold in any optimum where there are strictly positive fractions of switchers and stayers of both types. 


\section{References}

Cochrane, J.H., 1995. Time-consistent health insurance. Journal of Political Economy 103, 445-473.

Dowd, B., Feldman, R., 1992. Insurer competition and protection from risk redefinition in the individual and small group health insurance market. Inquiry $29,148-157$.

Hendel, I., Lizzeri, A., 2000. The role of commitment in dynamic contracts: evidence from life insurance. NBER Working Paper No. 7470, Cambridge.

Pauly, M.V., Kunreuther, H., Hirth, R., 1995. Guaranteed renewability in insurance. Journal of Risk and Uncertainty 10, 143-156.

van de Veen, W.P.M.M., van Vliet, R.C.J.A., Schut, F.T., van Barneveld, E.M., 2000. Access to coverage for high-risks in a competitive individual health insurance market: via premium rate restrictions or risk-adjusted premium subsidies? Journal of Health Economics 19, 311-339. 


\section{CESifo Working Paper Series}

(for full list see www.cesifo.de)

795 Marko Köthenbürger and Panu Poutvaara, Social Security Reform and Intergenerational Trade: Is there Scope for a Pareto-Improvement?, October 2002

796 Paul De Grauwe and Laura Rinaldi, A Model of the Card Payment System and the Interchange Fee, October 2002

797 Volker Böhm and Tomoo Kikuchi, Dynamics of Endogenous Business Cycles and Exchange Rate Volatility, October 2002

798 Mariam Camarero, Javier Ordóñez, and Cecilio Tamarit, The Euro-Dollar Exchange Rate: Is it Fundamental?, October 2002

799 Misa Tanaka, How Do Bank Capital and Capital Adequacy Regulation Affect the Monetary Transmission Mechanism?, October 2002

800 Jörg Baten and Andrea Wagner, Autarchy, Market Disintegration, and Health: The Mortality and Nutritional Crisis in Nazi Germany, 1933-1937, October 2002

801 Saku Aura, Uncommitted Couples: Some Efficiency and Policy Implications of Marital Bargaining, October 2002

802 Wolfram F. Richter, Delaying Integration of Immigrant Labor for the Purpose of Taxation, October 2002

803 Gil S. Epstein and Shmuel Nitzan, The Politics of Randomness, October 2002

804 John Hassler and José V. Rodriguez Mora, Should UI Benefits Really Fall over Time?, October 2002

805 Friedrich Breyer and Stefan Felder, The Dead-anyway Effect Revis(it)ed, October 2002

806 Assar Lindbeck and Solveig Wikström, E-exchange and the Boundary between Households and Organizations, November 2002

807 Dieter Bös, Contests Among Bureaucrats, November 2002

808 Steven Brakman, Harry Garretsen, and Marc Schramm, The Strategic Bombing of German Cities during World War II and its Impact on City Growth, November 2002

809 Florian Englmaier and Achim Wambach, Contracts and Inequity Aversion, November 2002

810 Sarbajit Sengupta, Delegating Recruitment under Asymmetric Information, December 2002 
811 Rajshri Jayaraman, On the Partial Public Provision of a Private Good, December 2002

812 Stéphanie Stolz, Banking Supervision in Integrated Financial Markets: Implications for the EU, December 2002

813 Christian Keuschnigg, Taxation of a Venture Capitalist with a Portfolio of Firms, December 2002

814 Inés Macho-Stadler and David Pérez-Castrillo, Settlement in Tax Evasion Prosecution, December 2002

815 Rainer Niemann and Dirk Simons, Costs, Benefits, and Tax-induced Distortions of Stock Option Plans, December 2002

816 Jan-Egbert Sturm and Barry Williams, Deregulation, Entry of Foreign Banks and Bank Efficiency in Australia, December 2002

817 V. Anton Muscatelli, Patrizio Tirelli, and Carmine Trecroci, Monetary and Fiscal Policy Interactions over the Cycle: Some Empirical Evidence, December 2002

818 Claude Hillinger, A General Theory of Price and Quantity Aggregation and Welfare Measurement, December 2002

819 Erkki Koskela and Ronnie Schöb, Optimal Capital Taxation in Economies with Unionised and Competitive Labour Markets, December 2002

820 Sheilagh Ogilvie, Guilds, Efficiency, and Social Capital: Evidence from German ProtoIndustry, December 2002

821 Hans Gersbach and Verena Liessem, Financing Democracy, December 2002

822 Costas Hadjiyiannis, Panos Hatzipanayotou, and Michael S. Michael, Optimal Tax Policies with Private-Public Clean-Up, Cross-Border Pollution and Capital Mobility, December 2002

823 François Ortalo-Magné and Sven Rady, Homeownership: Low Household Mobility, Volatile Housing Prices, High Income Dispersion, December 2002

824 Syed M. Ahsan and Panagiotis Tsigaris, Measuring the Social Discount Rate under Uncertainty: A Methodology and Application, December 2002

825 Kai A. Konrad, Altruism and Envy in Contests: An Evolutionarily Stable Symbiosis, December 2002

826 Robert S. Chirinko and Huntley Schaller, A Revealed Preference Approach to Understanding Corporate Governance Problems: Evidence from Canada, December 2002

827 Geir B. Asheim, Green National Accounting for Welfare and Sustainability: A Taxonomy of Assumptions and Results, December 2002 
828 Andrea Gebauer, Chang Woon Nam, and Rüdiger Parsche, Lessons of the 1999 Abolition of Intra-EU Duty Free Sales for Eastern European EU Candidates, December 2002

829 Giacomo Corneo, Work and Television, December 2002

830 Vivek H. Dehejia and Yiagadeesen Samy, Trade and Labour Standards - Theory, New Empirical Evidence, and Policy Implications, December 2002

831 Geir B. Asheim and Wolfgang Buchholz, A General Approach to Welfare Measurement through National Income Accounting, December 2002

832 Aaron Tornell and Frank Westermann, The Credit Channel in Middle Income Countries, January 2003

833 Gebhard Flaig, Time Series Properties of the German Monthly Production Index, January 2003

834 Campbell Leith and Jim Malley, Estimated Open Economy New Keynesian Phillips Curves for the G7, January 2003

835 Burkhard Heer and Bernd Süssmuth, Inflation and Wealth Distribution, January 2003

836 Erkki Koskela and Leopold von Thadden, Optimal Factor Taxation under Wage Bargaining - A Dynamic Perspective, January 2003

837 Carola Grün and Stephan Klasen, Growth, Income Distribution, and Well-Being: Comparisons across Space and Time, January 2003

838 Robert S. Chirinko and Ulf von Kalckreuth, On the German Monetary Transmission Mechanism: Interest Rate and Credit Channels for Investment Spending, January 2003

839 Sascha O. Becker, Andrea Ichino, and Giovanni Peri, How Large is the "Brain Drain" from Italy?", January 2003

840 Albert Berry and John Serieux, All About the Giants: Probing the Influences on Growth and Income Inequality at the End of the $20^{\text {th }}$ Century, January 2003

841 Robert Fenge and Martin Werding, Ageing and the Tax Implied in Public Pension Schemes: Simulations for Selected OECD Countries, January 2003

842 Robert Fenge and Martin Werding, Ageing and Fiscal Imbalances Across Generations: Concepts of Measurement, January 2003

843 Giovanni Andrea Cornia, The Impact of Liberalisation and Globalisation on Income Inequality in Developing and Transitional Economies, January 2003

844 Peter Fredriksson and Per Johansson, Program Evaluation and Random Program Starts, January 2003 
845 Bernd Hayo and Matthias Wrede, Fiscal Equalisation: Principles and an Application to the European Union, January 2003

846 Syed M. Ahsan and Jaideep Oberoi, Inequality, Well-being and Institutions in Latin America and the Caribbean, January 2003

847 Chang Woon Nam and Doina Maria Radulescu, The Role of Tax Depreciation for Investment Decisions: A Comparison of European Transition Countries, January 2003

848 V. Bhaskar and Steinar Holden, Wage Differentiation via Subsidised General Training, January 2003

849 Paloma Lopez-Garcia, Labour Market Performance and Start-up Costs: OECD Evidence, January 2003

850 Christian Keuschnigg and Soren Bo Nielsen, Public Policy for Start-up Entrepreneurship with Venture Capital and Bank Finance, January 2003

851 Yin-Wong Cheung, Menzie D. Chinn, and Eiji Fujii, China, Hong Kong, and Taiwan: A Quantitative Assessment of Real and Financial Integration, January 2003

852 Gregory D. Hess, The Economic Welfare Cost of Conflict: An Empirical Assessment, February 2003

853 Douglas J. Cumming and Jeffrey G. MacIntosh, Comparative Venture Capital Governance. Private versus Labour Sponsored Venture Capital Funds, February 2003

854 Eckhard Janeba and John Douglas Wilson, Decentralization and International Tax Competition, February 2003

855 Tapio Palokangas, Capital Accumulation and Employment Cycles in a Model of Creative Destruction, February 2003

856 Brendan Walsh, When Unemployment Disappears: Ireland in the 1990s, February 2003

857 Luis H. R. Alvarez and Erkki Koskela, A General Approach to the Stochastic Rotation Problem with Amenity Valuation, February 2003

858 Christian Schultz, Strategic Campaigns and Redistributive Politics, February 2003

859 Ernst Fehr and Joseph Henrich, Is Strong Reciprocity a Maladaptation? On the Evolutionary Foundations of Human Altruism, February 2003

860 Haizhou Huang, Dalia Marin, and Chenggang Xu, Financial Crisis, Economic Recovery and Banking Development in Former Soviet Union Economies, February 2003

861 Pedro Cardoso and Bernard M.S. van Praag, How Sustainable Are Old-age Pensions in a Shrinking Population with Endogenous Labour Supply?, February 2003

862 Volker Meier, Efficient Transfer of Aging Provisions in Private Health Insurance, February 2003 